\title{
Kim Holt: Pet hate is bullying
}

In this BMJ Confidential (BMJ 2014;349:g7093, doi:10.1136/ bmj.g7093) Kim Holt said that, if she could be invisible for 24 hours, she would like to attend the discussions at the Department of Health on the Francis review. In editing the piece, we mistakenly referred to this as being the Francis inquiry into the Mid Staffordshire Foundation Trust, which was chaired by Robert Francis and published in February 2013. The Francis inquiry to which Holt was referring is an ongoing investigation into whistleblowing in the NHS, which is also being conducted by Robert Francis and is due to report in the New Year. We apologise for the error.

Cite this as: BMJ 2014;349:97379

๑ BMJ Publishing Group Ltd 2014 